\title{
PENINGKATAN LAYANAN POSPAY DENGAN TEKNOLOGI BUSINESS PROCESS ANALYSIS (BPA) PADA PT. POS INDONESIA AREA KOTA MALANG
}

\author{
Rizqiyatul Khoiriyah \\ Prodi Sistem Informasi, Universitas Gajayana Malang, Jawa Timur 65144 \\ rizqiyatul@unigamalang.ac.id
}

\begin{abstract}
ABSTRAK
PT. Pos Indonesia memiliki layanan pos payment (pospay) atau System Online Payment Point (SOPP). Layanan pospay yang sudah berjalan harus terus ditingkatkan agar dapat berkembang dengan baik. Hal ini maka menjadi penting dilakukan analisis proses bisnis yang berjalan pada layanan pospay di PT. Pos Indonesia Area Kota Malang agar nantinya dapat diketahui dan diidentifikasi peluang peningkatan proses bisnis yang lebih baik. Tujuan penelitian ini yaitu untuk menganalisis proses-proses bisnis yang berjalan pada layanan payment (pospay) dan mengidentifikasi peluang peningkatan proses bisnis layanan payment (pospay) pada PT. Pos Indonesia Kota Malang. Berdasarkan hasil analisis proses bisnis yang sedang berjalan maka ditemukan proses bisnis layanan payment (pospay) PT. Pos Indonesia area Kota Malang telah berjalan sesuai prosedur yang ada namun memiliki keterbatasan pada sistem antrian yaitu pelanggan yang akan melakukan pengiriman barang dan pembayaran pospay masih menggunakan antrian satu jalur. Dari kelemahan dan keterbatasan iniliah maka diusulkanlah proses bisnis dengan sistem antrian dua jalur namun juga dapat berjalan fleksibel dengan sistem antrian satu jalur sebelumnya. Dengan adanya sistem antriaan dua jalur yang diusulkan maka dapat mengefisien waktu serta dapat meningkatkan jumlah pelanggan yang dapat dilayani petugas loket antrian PT. Pos Indonesia area Kota Malang.
\end{abstract}

Kata kunci : analisis proses bisnis, layanan, pospay

\begin{abstract}
PT. Pos Indonesia has a postal payment service (postpay) or System Online Payment Point (SOPP). Postpay services that are already running must be continuously improved so that they can develop properly. This makes it important to analyze the business processes that run on the postpay service at PT. Pos Indonesia Malang City Area so that later it can be known and identified opportunities for better business process improvement. The purpose of this study is to analyze the business processes that run on payment services (postpay) and identify opportunities to improve the payment service business process (postpay) at PT. Pos Indonesia Malang City. Based on the analysis of ongoing business processes, it was found that the payment service business process (postpay) of PT. Pos Indonesia in the Malang City area has been running according to existing procedures but has limitations on the queuing system, namely customers who will send goods and postpay payments still use a one-way queue. From these weaknesses and limitations, a business process with a two-lane queuing system was proposed, but it could also run flexibly with the previous one-line queuing system. The proposed two-lane queuing system, it can save time and increase the number of customers that can be served by PT. Pos Indonesia in Malang City area.
\end{abstract}

Keywords: business process analysis, services, pospay 


\section{PENDAHULUAN}

PT. Pos Indonesia (Persero) merupakan salah satu perusahaan Badan Usaha Milik Negara (BUMN) di bidang jasa pengiriman / ekspedisi pos nasional atau internasional yang didirikan pada tahun 1746 oleh Gub.Jendral G.W Baron Van Imhoft. PT. Pos Indonesia mengalami perubahan bentuk badan hukum dari awalnya berbentuk Perum Pos dan Giro menjadi PT. Pos Indonesia dengan modal bisa berasal dari negara dan penjualan saham kepada masyarakat [1]. Awal mulanya PT. Pos Indonesia hanya bergerak dalam bidang jasa pengiriman surat dan paket. Kemudian mengembangkan layanannya yaitu ekspedisi, surat / paket, jasa finansial, serta logistik barang. Dalam mengembangkan bisnisnya di bidang keuangan, PT. Pos Indonesia memiliki layanan pos payment (pospay) atau System Online Payment Point (SOPP) yaitu merupakan layanan pembayaran transaksi online untuk tagihan atau rekening mitra kerja PT. Pos Indonesia [2]. Layanan dalam SOPP yang disediakan yaitu pembayaran tagihan listrik, pajak kendaraan bermotor, asuransi, kartu kredit, air minum (PDAM), angsuran kredit, pulsa, sodaqoh / infaq, dan sebagainya. Dengan adanya sistem payment ini proses pembayaran transaksi dapat lebih efisien dilakukan serta masyarakat dapat pula mengetahui jumlah tagihan secara langsung sebelum proses pembayaran [3].

Sumber penghasilan terbesar kedua

PT. Pos Indonesia setelah layanan surat dan paket adalah layanan jasa keuangan sebesar Rp. 966,27 M per tahun. Dan sebagai penyumbang paling besar penghasilan tersebut berasal dari layanan pospay yaitu 531,2 M [4]. Layanan pospay yang sudah berjalan harus terus ditingkatkan agar dapat berkembang dengan baik. Peningkatan layanan dapat dilihat dari sejauh mana proses yang berjalan di layanan tersebut sehingga nantinya dapat dilakukan evaluasi. Selain itu, untuk mewujudkan tujuan PT. Pos Indonesia dalam melayani masyarakat secara penuh, PT. Pos Indonesia membutuhkan anggaran yang sesuai dengan kebutuhan organisasi dalam melayani masyarakat [5]. Proses-proses yang sudah berjalan tersebut perlu dianalisis dan dievaluasi guna mencari peluang peningkatan proses bisnis yang lebih baik. Atas dasar inilah maka penting dilakukan dan diperlukan analisis proses bisnis yang berjalan pada layanan pospay di PT. Pos Indonesia Area Kota Malang agar nantinya dapat diketahui dan diidentifikasi peluang peningkatan proses bisnis yang lebih baik. Tujuan penelitian ini yaitu untuk menganalisis proses-proses bisnis yang berjalan pada layanan payment (pospay) dan mengidentifikasi peluang peningkatan proses bisnis layanan payment (pospay) pada PT.Pos Indonesia Kota Malang.

Analisis proses bisnis merupakan sekumpulan aktivitas serta permasalahanpermasalahan yang terjadi pada pelaksanaannya [6]. Tiap analisis dan pemodelan proses digunakan sebagai blueprint bagi sekumpulan proses bisnis, sedangkan gambaran atau model proses / aktivitas digunakan sebagai blueprint bagi sekumpulan aktivitas [7] [8]. Dengan melakukan analisis proses bisnis yang berjalan pada layanan pospay di PT. Pos Indonesia Area Kota Malang, diharapkan nantinya dapat diketahui dan diidentifikasi peluang peningkatan proses bisnis yang 
lebih baik dengan rekomendasi atas perbaikan kelemahan dan hambatan yang ditemui saat melakukan analisis proses bisnis tersebut. Hal ini juga selaras dengan misi PT. Pos Indonesia untuk selalu berinovasi dan bersaing di era teknologi informasi saat ini, maka dibutuhkan pula peningkatan layanan agar lebih banyak pengguna yang memanfaatkan layanan pospay.

\section{METODE PENELITIAN}

Pengumpulan data oleh peneliti dilakukan melalui observasi dengan cara mengamati secara langsung seperti apa proses yang berjalan termasuk proses-proses layanan pospay yang sedang berjalan mulai dari proses pelanggan datang ke PT. Pos Indonesia area kota Malang lalu mendapatkan nomor antrian yang diberikan petugas antrian kemudian proses menunggu giliiran pemanggilan nomor antrian hingga proses pembayaran selesai. Selain observasi, peneliti melakukan wawancara langsung ke bagian petugas yang melayani pembayaran pospay dan kepada pelanggan yang kerap melakukan pembayaran melalui PT. Pos Indonesia area kota Malang. Sumber data dalam analisis proses bisnis pospay ini didapat dari pegawai bagian pospay PT. Pos Indonesia area Kota Malang. Adapun data yang digunakan adalah standar operasional prosedur layanan pospay termasuk proses awal hingga akhir sukses melakukan pembayaran pospay. Setelah melakukan pengumpulan data kemudian dilakukan analisis dengan cara mengidentifikasi pelaku proses bisnis yang terlibat dalam proses pembayaran tagihan pada layanan pospay di PT. Pos Indonesia area kota Malang; mengidentifikasi aktivitas- aktivitas dari setiap pelaku proses bisnis yang terlibat dalam proses bisnis layanan pospay; menggambarkan model proses pembayaran tagihan menggunakan pospay; mengidentifikasi permasalahan yang terjadi dalam proses bisnis layanan pospay; dan mendeskripsikan hasil analisis dengan diagram aktivitas.

\section{HASIL DAN PEMBAHASAN}

Analisis Proses Bisnis yang Sedang Berjalan di PT. Pos Indonesia Area Kota Malang

PT. Pos Indonesia area kota Malang memiliki 13 loket, yang mana masing- masing loket melayani pembayaran dan pengiriman surat dan barang, hanya saja loket pengiriman barang di atas $2 \mathrm{~kg}$ tidak menjadi satu dengan 13 loket yang ada, namun masih terpisah ruangannya. Hasil dari observasi menunjukkan bahwa terdapat pelanggan yang salah loket setelah melakukan antrian, pelanggan yang seharusnya akan melakukan pengiriman barang mengantri di loket pembayaran dan pengiriman surat dan paket dengan satu jalur. Proses antrian yang berjalan dengan cara melakukan pemanggilan no.antrian pelanggan kemudian mengarahkan pelanggan ke loket yang kosong. Berdasarkan hasil wawancara ditemukan bahwa pelanggan yang melakukan transaksi pembayaran maupun pengiriman, dari hasi wawancara tersebut didapatkan informasi bahwa pelanggan dalam melakukan pembayaran ataupun pengiriman harus antri 7-10 menit, tergantung jumlah pelanggan yang datang. Sedangkan untuk petugas layanan pospay, diperoleh informasi bahwa setiap pelanggan yang datang, petugas selalu menanyakan keperluan pelanggan dengan 
waktu yang cukup menyita. Bahkan tidak jarang pelanggan menjadi bingung ke loket mana yang sebenarnya harus dituju. Sehingga dari proses ini berdampak pada jumlah pelanggan yang akan melakukan pembayaran melalui layanan pospay, karena di anggap lama dalam proses antrian.

Analisis Proses Layanan Pospay yang Sedang Berjalan di PT. Pos Indonesia Area Kota Malang

Dalam melakukan transaksi pembayaran tagihan menggunakan pospay ada beberapa langkah yang harus diketahui oleh pelanggan, diantaranya terangkum dalam gambar berikut:

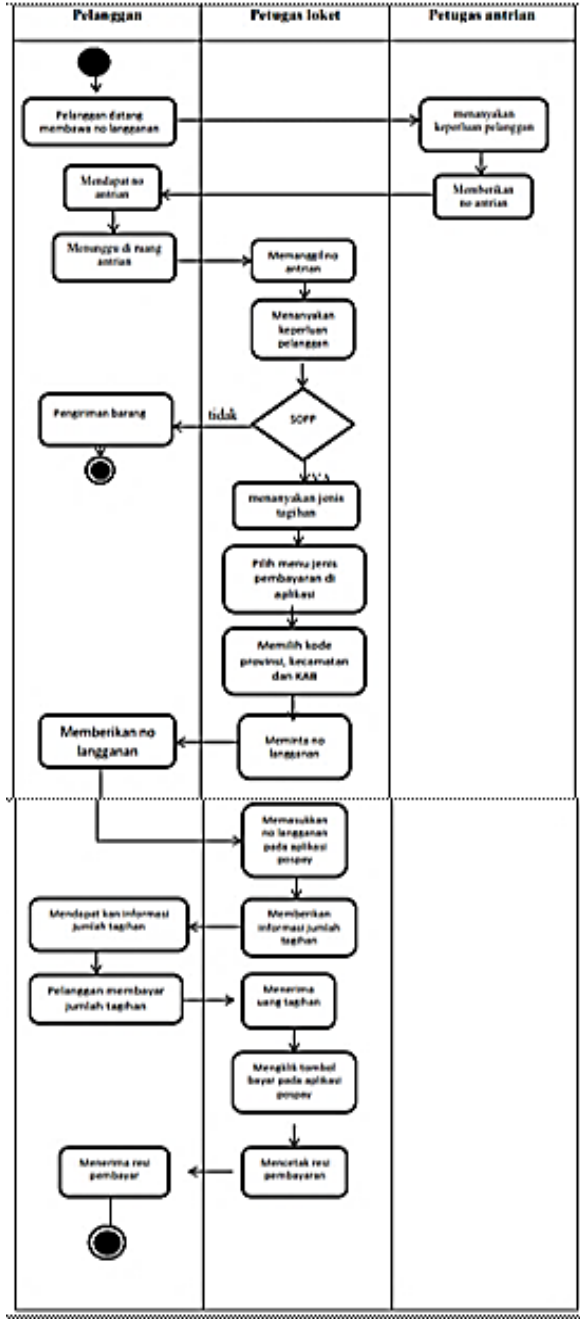

Gambar 1. Diagram Aktivitas Layanan Pospay yang Sedang Berjalan

\section{Analisis Kelemahan Proses Layanan Pospay di PT. Pos Indonesia Area Kota Malang}

Beberapa kendala muncul pada saat saat pelayanan sistem pospay, yaitu masih memiliki keterbatasan sistem antrian karena masih menggunakan antrian satu jalur untuk pelanggan. Banyak pelanggan yang datang mengeluh dengan sistem antrian yang hanya ada satu jalur sehingga proses antrian lebih lama ketika petugas loket memanggil no antrian petugas loket belum mengetahui pelanggan yang di panggil ingin melakukan pembayaran tagihan atau ingin melakukan pengiriman barang, ketika pelanggan sudah dipanggil oleh petugas loket kemudian menanyakan keperluan pelanggan dahulu. Jika pelanggan akan melakukan pengiriman barang di atas $2 \mathrm{~kg}$ maka petugas loket mengarahkan pelanggan ke loket yang melayani pengiriman barang. Namun, ketika pelanggan akan melalukan pembayaran tagihan maka petugas loket langsung melayani pelanggan dan meminta no langganan. Proses menanyakan keperluan pelanggan oleh petugas loket akan menyita waktu tersendiri dan tidak jarang pelanggan menjadi bingung ke loket mana yang sebenarnya harus dituju.

\section{Rekomendasi Proses Bisnis Layanan Pospay yang Diusulkan}

Proses bisnis yang diusulkan dalam pelayanan pospay adalah pada sistem antrian. Berikut ini adalah uraiannya :

a. Sistem antrian yang selama ini hanya satu jalur untuk semua layanan akan ditambahkan menjadi sistem antrian dua jalur, yaitu loket antrian bagi pelanggan yang akan melakukan pembayaran tagihan (pospay) dan loket antrian bagi 
pelanggan yang melakukan pengiriman barang dan dokumen.

b. Dengan membedakan loket antrian maka menu antrian pada mesin antrian juga perlu dibedakan yaitu untuk pembayaran pospay (kode A) dan pengiriman barang (kode B).

c. Sistem antrian dapat berjalan fleksibel yaitu pada saat tertentu menggunakan dua jalur dan pada saat yang lain juga bisa satu jalur.

Secara umum dapat digambarkan melalui diagram aktivitas sebagai berikut :

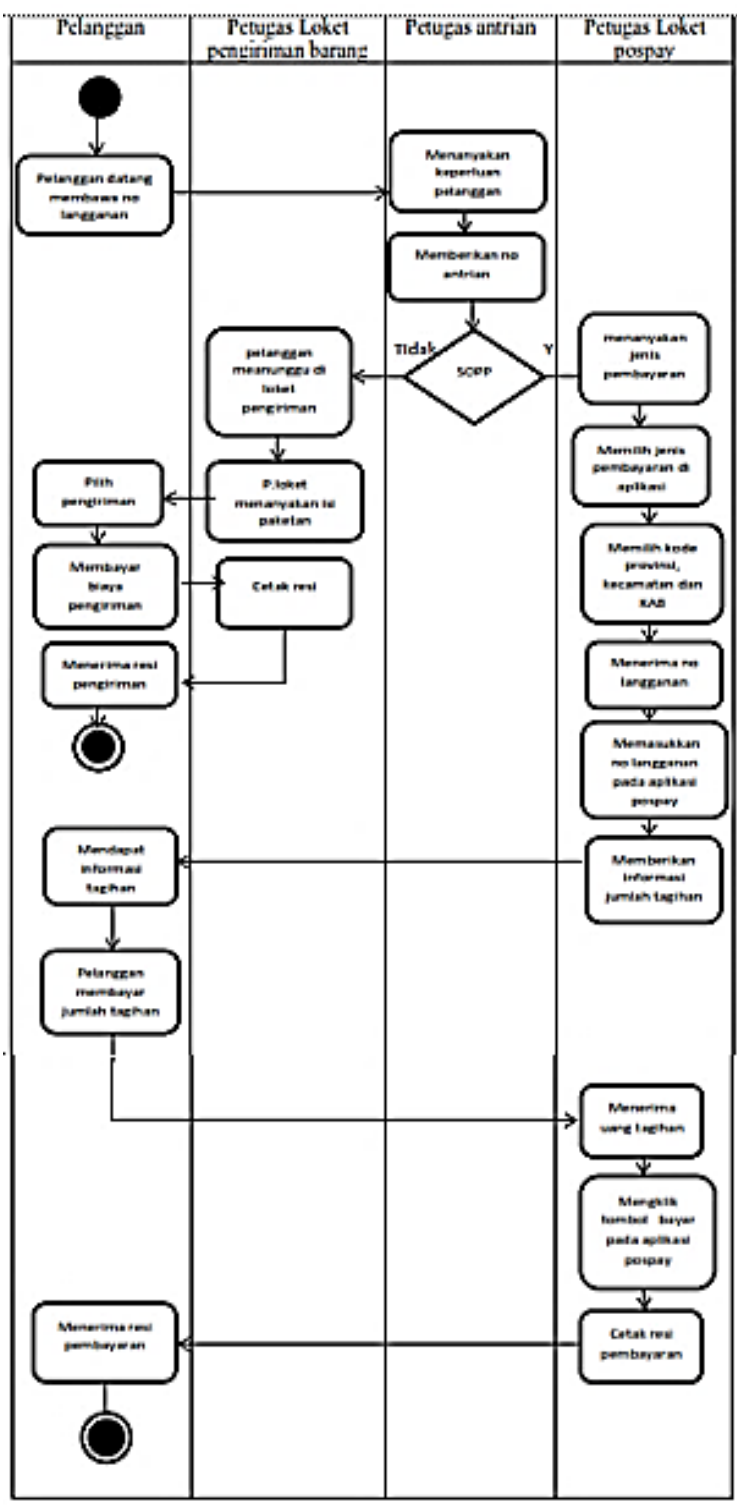

Gambar 2. Diagram Aktivitas Layanan Pospay yang Diusulkan (Rekomendasi)
Perbandingan Proses Layanan Pospay yang Sedang Berjalan Dengan Sistem yang Diusulkan

Tabel 1. Perbandingan Proses layanan pospay yang Sedang Berjalan Dengan Proses Bisnis yang Diusulkan

\begin{tabular}{ccc}
\hline Noses yang & Proses Bisnis \\
No & $\begin{array}{c}\text { Sedang } \\
\text { Berjalan }\end{array}$ & yang Diusulkan \\
& \\
\hline
\end{tabular}

Calon pelanggan Calon pelanggan mendapatkan no mendapat no antrian satu jalur antrian sesuai ke tidak adapembeda perluan jika akan antara calon melakukan pelanggan yang akan membayar dan yangakan melakukan pembayaran tagihan pada aplikasi pospay jika kode no antrian A untuk pengiriman. pembayaranpospay dan B untuk pengiriman barang.

Ketika Ketika mengantri mengantri calon pelanggan harus mengantri jadi satu antara pelanggan yang akan melakukan pengiriman barang dengan pelanggan yang akan melakukan pembayaran.

Ketika pelanggan melakukan pembayaran atau pengiriman loket yang di gunakan menjadi satu. calon pelanggan mengantri suda terpisah antara pelanggan pengirim barang dan pelanggan yang membayar tagihan.

Petugas loket selalu

Ketika Pelanggan melakukan pengiriman atau pembayaran menggunakan loket yang berbeda. Sesuai kebutuhan. Petugas loket tidak perlu menanyakan 


$\begin{array}{ll}\text { menanyakan } & \text { keperluan } \\ \text { keperluan } & \text { pelanggan karna } \\ \text { pelanggan ingin } & \text { antrian sudah } \\ \text { melakukan } & \text { dipisahkan } \\ \text { pembayaran } & \text { sehingga petugas } \\ \text { atau pengiriman } & \text { bisa tahu } \\ & \text { pelanggan yang } \\ & \text { datang akan } \\ & \text { melakukan } \\ & \text { pembayaran atau } \\ & \text { pengiriman. } \\ & \text { Loket sudah di } \\ \text { Semua loket } & \text { bedakan antara } \\ \text { melayani } & \text { loket pembayaran } \\ \text { transaksi } & \text { dan loket } \\ \text { pelanggan. } & \text { pengiriman } \\ \end{array}$

\section{KESIMPULAN}

Proses bisnis layanan payment (pospay) PT. Pos Indonesia area Kota Malang telah berjalan sesuai prosedur yang ada, yaitu pelanggan datang dan mengambil no antrian lalu dipanggil ke loket dan membayar tagihan. Namun proses layanan pospay memiliki keterbatasan pada sistem antrian yaitu pelanggan yang akan melakukan pengiriman barang dan pembayaran pospay masih menggunakan antrian satu jalur, sehingga petugas loket dan pelanggan membutuhkan waktu tersendiri untuk menanyakan keperluan dan tempat loket yang sesuai. Berdasarkan hal tersebut maka diusulkanlah proses bisnis sistem antrian dua jalur dengan membedakan antrian pembayaran pospay dengan pengiriman barang sehingga akan menghemat waktu layanan dan waktu tunggu antrian. Sistem antrian dua jalur dapat berjalan fleksibel dengan sistem antrian satu jalur pada saat keadaan tertentu misal saat pelanggan akan menggunakan dua layanan sekaligus yaitu pembayaran pospay sekaligus pengiriman barang maka akan dilayani di loket yang sama. Dengan adanya sistem antriaan dua jalur yang diusulkan maka dapat mengefisien waktu serta dapat meningkatkan jumlah pelanggan yang dapat dilayanai loket antrian PT. Pos Indonesia area Kota Malang.

\section{TERIMA KASIH}

Terima kasih kami sampaikan untuk Tim Bagian Pospay PT. Pos Kota Malang, segenap citivas akademik Program Studi Sistem Informasi Universitas Gajayana beserta pihak-pihak yang telah berpartisipasi dalam penelitian ini.

\section{DAFTAR PUSTAKA}

[1] M. Randa and A. S. Dewi, "PENGARUH KUALITAS PELAYANAN TERHADAP INOVASI LAYANAN PT. POS INDONESIA SEBAGAI UPAYA MENJAGA EKSISTENSI DI ERA PERSAINGAN GLOBAL (Studi Kantor Pos Padang)," vol. 7, no. 2, pp. 647-660, 2019, doi: 10.31219/osf.io/ds38m.

[2] R. Arisandi, "Penerapan System Online Payment Point ( Sopp ) Dalam Pembayaran Rekening Listrik Di Pt . Pos ( Persero ) Cabang Kota Samarinda," eJournal Ilmu Pemerintah., vol. 1, no. 2, pp. 575-587, 2013, [Online]. Available: ejournal.ip.fisip.unmul.ac.id.

[3] R. Dewi, "ANALISIS SISTEM DAN PROSEDUR PEMBAYARAN PDAM MELALUI POSPAY GUNA MENDUKUNG PENGENDALIAN INTERN (Studi Pada Kantor Pos Pusat Kabupaten Nganjuk)," J. Adm. Bisnis S1 Univ. Brawijaya, vol. 15, no. 1, p. 84611, 2014.

[4] A. G. Herucakra, A. F. Santoso, and R. Hanafi, "Analisis dan Perancangan Enterprise Architecture untuk 
Mendukung Fungsi Terkait System Online Payment Point Menggunakan Framework TOGAF ADM pada PT Pos Indonesia," eProceedings Eng., vol. 2, no. 1, pp. 1012-1021, 2015.

[5] M. Jupri, H. Hamka, and R. Budiono, "Implementation of Performance Measurement Systems at PT. Pos Indonesian," Int. J. Business, Econ. Soc. Dev., vol. 1, no. 1, pp. 40-45, 2020, doi: 10.46336/ijbesd.v1i1.17.

[6] M. A. Ramdhani, "Pemodelan Proses Bisnis Sistem Akademik Menggunakan Pendekatan Business Process Modelling Notation (BPMN) (Studi Kasus Institusi Perguruan Tinggi Xyz)," J. Inf., vol. 7, no. 2, pp. 83-93, 2015.

[7] M. Y. Permatasari, I. Aknuranda, and N. Y. Setiawan, "Analisis dan Perbaikan Proses Bisnis dengan menggunakan Teknik Esia ( Studi Kasus : Departemen Produksi PT XYZ )," J. Pengemb. Teknol. Inf. dan Ilmu Komput. Univ. Brawijaya, vol. 2, no. 3, pp. 1227-1236, 2018.

[8] R. Shapiro et al., BPMN 2.0 Handbook Second Edition: Methods, Concepts, Case Studies and Standards in Business Process Modeling Notation (BPMN). 2012. 